obliga sus bienes presentes, y futuros, por amplio poder a los Sres. Jueces de esta Villa para/ que la Compelan como por Sentencia definitiva pa-/ sada en autoridad de cosa juzgada y consentida, que / por tal la recive, renuncia las Leyes fueros, y privi/ legios de su favor, memoria de edad, y bene ficio de / restitucion ni integracion que le compete. Y asi lo / otorgan, y firman, a quienes doy fee conozco siendo / testigos D. Bernardino Tolosa, D. Juan Jose Sanchez / Pescador y D Jose Salanova, vecinos y residentes en esta Corte./

Maria de la Concepcion Mariategui, (rubricado) Franc ${ }^{a}$ Javier de Mariategui (rubricado) / Ramona Asperilla (rubricado) Antemy/ Antonio Lopez de Salazar (rubricado)».

JuAN JoSÉ JunQuera y MATO

\title{
ADDENDA AL CAPRICHO DE GOYA «TÚ QUE NO PUEDES»
}

En el número de Archivo Español de Arte, correspondiente a diciembre del 2004, puse en relación formal - no de contenido- algunos grabados de los Caprichos, con otros que ilustraban un Exemplario, publicado en Zaragoza en 1531, y que pudieron servir de inspiración al pintor aragonés ${ }^{1}$.

Revisando el libro de Randall, sobre márgenes miniados, he tropezado con un motivo más cercano al capricho Tú que no puedes (fig. 1), que el propuesto en mi anterior trabajo. Se trata de una miniatura en la que aparece un hombre cargando un asno sobre sus espaldas (fig. 2), de la misma manera que en la escena goyesca. Randall sugiere que puede tratarse de la ilustración de un proverbio o de una fábula ${ }^{2}$.

Relacionado con esta escena existe un refrán recogido por el Marqués de Santillana en su Refranero: «No es de seso traer el asno en peso», y que Antonio Castillo de Lucas identifica con la insensatez del hombre ${ }^{3}$, interpretación que puede concordar con lo expresado por Goya en su grabado.

También, releyendo la Nave de los Locos de Sebastián Brandt, publicada en Basilea en 1493, vemos una escena similar (fig. 3), con un epígrafe referido a la estupidez humana, especialmente representada por los insensatos que se dejan abrumar por cualquier motivo, y que también podría convenir como precedente literario y artístico del grabado de Goya: «Muchos necios que estultos son en múltiples sentidos, están en este aprieto: sentadoles está el asno en las espaldas» 4 .

No se ha sabido nunca si Goya tuvo una biblioteca, pero tanto el Exemplario, como el Refranero de Santillana y la Nave de los locos, podrían haber sido libros que, por su temática, no solo era lógico de contar en la biblioteca de Iriarte, por ejemplo, sino como propiedad del mismo Goya, ya que el contexto de ellas casaba perfectamente con el talante sentencioso y popular de algunas producciones del pintor aragonés.

IsABel MATeo GómEZ

${ }^{1}$ I. Mateo Gómez, «A propósito de algunos Caprichos de Goya y un Exemplario aragonés de 1531», Archivo Español de Arte, LXXVII, 2004, pp. 411-415, figs. 1 y 2. Involuntariamente omití en este trabajo, que el Exemplario me fue regalado por Benito Navarrete, a quien agradezco, además, no pocas opiniones.

${ }^{2}$ L. M. C. Randall, Images in the margins of Gothic manuscripts, Berkeley, 1966, p. 331.

${ }^{3}$ A. Castillo de Lucas, «Ensayo antropológico del Marqués de Santillana y de su Refranero», Archivo Iberoamericano de Historia de la medicina y Antropología médica, vol. XI, fasc. 3, 1959, pág. 37, nº 490 (en el Marqués de Santillana, refrán $n^{\circ} 477$ )

${ }^{4}$ Ed. Akal, 1998, pp. 244-245.

$A E A$, LXXVIII, 2005, 309, pp. 83 a 105 

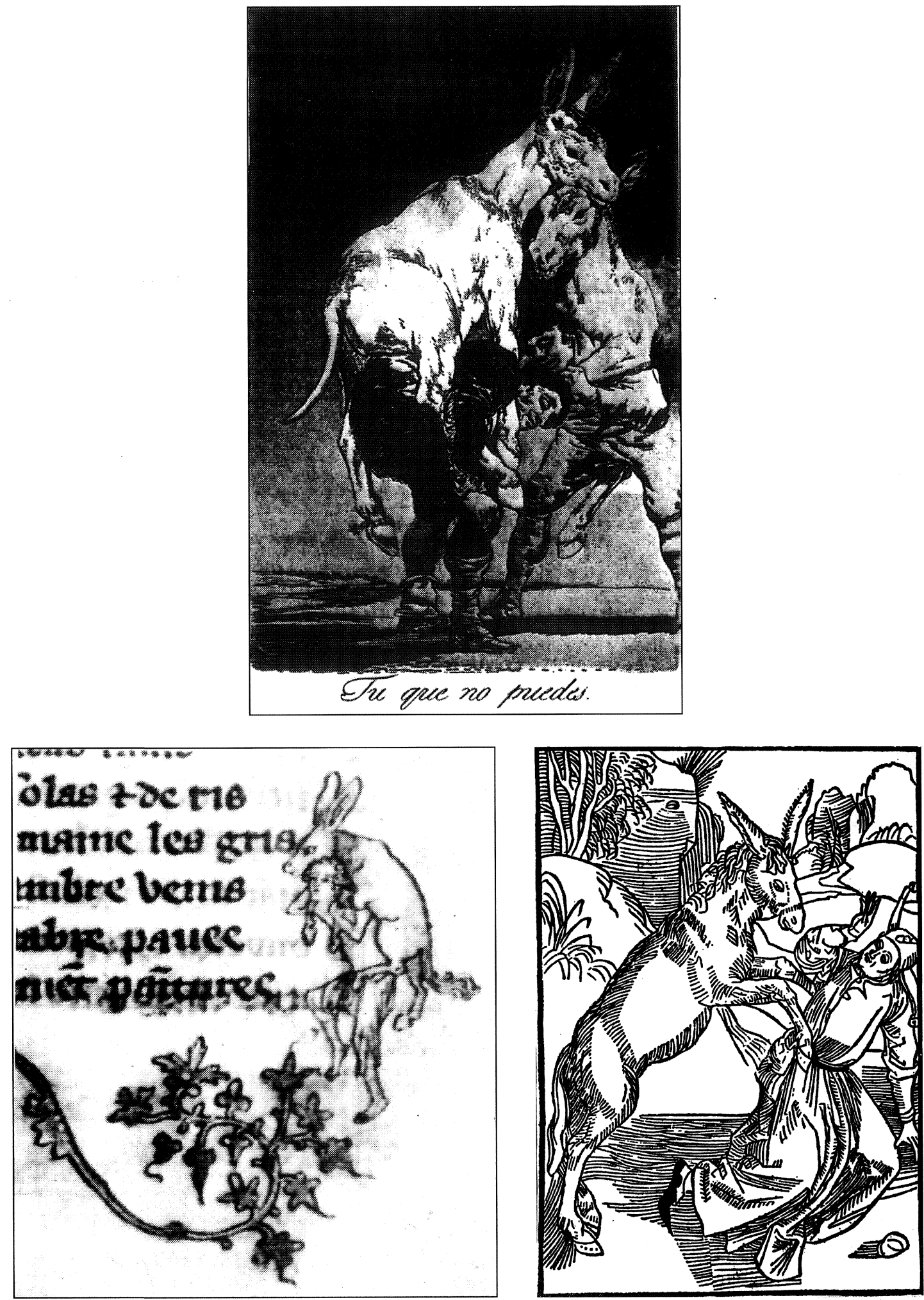

Fig. 1. Goya: Capricho «Tú que no puedes».

Fig. 2. Orla miniada, s. xIv-xv.

Fig. 3. S. Brandt, La nave de los locos. 